Academic Platform Journal of Engineering and Science

journal homepage: $\underline{\text { http://apjes.com/ }}$

\title{
Çokdeğişkenli Ampirik Mod Ayrıştırımı ile İçsel Bağlantı Ağları Kestirimi
}

\author{
*1 Adil Deniz Duru \\ ${ }^{1}$ Marmara Üniversitesi, Spor Bilimleri Fakültesi, Antrenörlük Eğitimi Bölümü, İstanbul/Türkiye \\ deniz.duru@marmara.edu.tr, (iD \\ Araștırma Makalesi \\ Geliş Tarihi: 04.09.2018 \\ Kabul Tarihi: 22.10.2018
}

$\ddot{O} z$

Beyin fonksiyonlarının haritalanması, elektriksel aktivite ve hemodinamik bilgiler 1şı̆̆ında gerçekleştirilebilmektedir. Kanın oksijenlenmesine bağıl (BOLD) sinyali girişimsel olmayacak şekilde fonksiyonel manyetik rezonans görüntülemesi (fMRG) ile elde edilebilmektedir. Herhangi bir mental görev gerçekleştirilmediği esnada bile beyin bölgelerinde aktivasyonlar izlenebilmektedir. Bu aktivasyon izgelerine dinlenim durumu beyin ağları adı verilmektedir. Bu çalışmanın amacı, BOLD zaman serilerinin doğrudan kendilerini kullanmak yerine, dekompoze edimesi ile elde edilen alt zaman serilerinin birbirleri arasındaki koherans bilgisine dayanarak haritalama işlemi yapmaktır. Ayrıştırma işlemi için çokdeğişkenli ampirik mod dekompozisyonu kullanılmıştır (MEMD). Beyin dokusunda sınırlı sayıda düğüm bölgesi anatomik şablonlar yardımı ile belirlenmiştir. Belirlenen anatomik bölgelere ait zaman serileri girdi olarak kullanılmıştır. Her düğüm alt zaman serisinin diğer düğümlerin alt zaman serileri arasındaki koherans bilgisi hesaplanarak, frekans alanında korelasyonlar belirlenmiştir. Böylece, herhangi bir önbilgi empoze edilmeden BOLD zaman serisinin alt bileşenlerinin spektral özelliklerinin incelenmesi sağlanmıştır.19 gönüllüden alınan dinlenim durumu fMRG verisi önişleme tekniklerinin uygulanmasından sonra analiz edilerek spektral özellikleri incelenmiştir. Elde edilen dört farklı bileşenin zaman serilerinin spektral özellikleri 0.007, 0.014, 0.03 ve 0.064 Hz frekanslarında tepe değerler almıştır. Birinci bileşende işitsel fonksiyonların ve görsel işlevlerin yürütülmesinde rol oynayan süperiyor temporal gyrus ve oksipital bağlantılar, ikinci bileşende varsayılan kip ağının önemli bileşenleri olan posteriyor ve anteriyor singulat izlenmişir. Üçüncü bileşende $0.03 \mathrm{~Hz}$ ile $0.06 \mathrm{~Hz}$ civarında dikkat ağının düğümleri gözlenmiştir. Dördüncü bileşende ise superiyor temporal girus bağlantıları baskın olarak izlenmiştir.

Anahtar kelimeler: Ampirik Mod Dekompozisyonu, BOLD, fonksiyonel beyin ağları, Koherans

\section{Estimation of Intrinsic Connectivity Networks by Multivariate Empirical Mode Decomposition}

\author{
${ }^{1}$ Adil Deniz Duru \\ ${ }^{1}$ Marmara University, Faculty of Sport Sciences, Department of Sports Coaching Education, İstanbul/Turkey \\ deniz.duru@marmara.edu.tr
}

\begin{abstract}
Functional brain mapping is based on electrical and haemodynamic changes occured in the brain. Blood oxeygenated level dependency (BOLD) signal can be non-invasively collected through the use of functional Magnetic Resonance Imaging (fMRI). Brain functional activity can also be observed in the absence of a given task. These activation patterns are named as brain resting state networks. The aim of this study is, to perform functional brain mapping using the coherence metrics between the decomposed BOLD time series insted of using the raw BOLD time series. Multivariate Emprical mode decomposition procedure is applied for the BOLD series decomposition. Limited number of anatomical locations are selected for node positions using anatomical templates. Further each subseries are used to compute the correlations in frequency domain as coherence values between the node points. By this way, spectral properties of subseries are investigated without imposing any a priori information. FMRI data were collected from 19 volunteers and the preprocessing steps are applied prior to analysis of spectral properties. Four subcomponents whose spectral peaks are determined at $0.007 \mathrm{~Hz}, 0.014 \mathrm{~Hz}, 0.03 \mathrm{~Hz}$ and $0.064 \mathrm{~Hz}$ were determined. In the first component, superior temporal gyrus and occipital lobe connections were exhibited which contribute to the functionality of
\end{abstract}


the auditory and visual networks. Posterior and anterior cingulate areas that are the major parts of the default mode network were found to be present in the second component. In the third component, nodes of the attention network were observed with a center frequency of $0.03 \mathrm{~Hz}$ to $0.06 \mathrm{~Hz}$. Additionally, connections of superior temporal gyrus were observed in the fourth component.

Keywords: Emprical Mode Decomposition, BOLD, functional brain network, Coherence

\section{GİRİş}

Beyin, çok sayıda fonksiyonel olarak farklılaşmış bölgelerin birbirleri ile bilgi aktarımı gerçekleştirmesi ile karmaşık bilişsel işlevleri icra eder. Birbirleri ile etkileşimde olan beyin bölgeleri genellikle benzer zamansal nöronal aktivasyonlara sahiptirler. Bu zamansal korelasyona sahip bölgeler ağ olarak adlandırılırlar ve bu ağı oluşturan bölgeler fonksiyonel bağlantılı olarak tanımlanmaktadırlar [1].

Anatomik beyin görüntülemesinde Manyetik Rezonans Görüntüleme altın standart modalite olarak kabul edilirken, son onlu yıllarda beyin fonksiyonlarının izlenmesinde de sıklıkla kullanılmaya başlanmıştır. Venöz kanda paramanyetik özelliğe sahip deoksihemoglobin değişiklikler non-invasiv olarak beyin dokusunda kontrast yaratmaya olanak vermektedir [2]. Yüskek uzaysal çözünürlükle beyin dokusunda kanın oksijenlenmeye bağlı (BOLD) değişimlerinin ölçülmesinden yola çıkılarak, beyin aktivasyonlarının tespit edilmesine yönelik araştırmalar gerek klinikte gereksede temel bilim çalışmalarında yer almaktadır. Verilen bir ödev esnasında gerçekleştirilen BOLD ölçümlerinin dinlenim durumuna göre değişikliğinden yola çıkılarak, icra edilen zihinsel görevin beynin hangi bölgelerinden kaynaklandığı izlemek, veri güdümlü veya parametrik analiz metodların uygulanmasıyla mümkün olmaktadır.

Beyin aktivitesinin sürekli olduğu temelinde, herhangi bir ödevin icra edilmediği süreçtede, beyin fonksiyonların izlenmesi araştırmacılara önemli bilgiler sunmaktadır. Ödev icra edilmediği süreçte, benzer zamansal süreçlere sahip nöronal grupların oluşturdurduğu gruplara dinlenim durumu beyin ağları adı verilmektedir.

Yapılan öncül fonksiyonel bağlantısallık çalışmalarında, dinlenim durumundaki BOLD ölçümlerinden yola çıkılarak, sağ ve sol birincil motor bölgenin fonksiyonel bağlantısallığı Biswal ve ark. [3] tarafından gösterilmiştir. Dinlenim durumu içsel bağlantı ağları araştırmalarında, yaşlanma, herhangi bir konuda uzmanlaşma ve klinik rahatsızlık durumlarını beyin fonksiyonel ağları ile ilişkilendiren çok sayıda çalışma yapılmıştır. Fonksiyonel ağların uzaysal genişliklerinin yanısıra, zamansal örüntülerinin frekans spektrumlarıda incelenmiştir.

Yaşlanma ile dinlenim durumu bağlantısallık haritalarında uzaysal genişlik ve düşük frekans gücünün ters ilintili olduğu gösterilmiştir [4]. Diğer bir çalışmada yaşlanmaya bağlı olarak korpus kollosum dejenenerasyonun beyin aktivasyonunda oluşturduğu artışın hemisferler arasındaki bağlantısallık üzerindeki etkileri Langan ve ark. tarafından basit bir motor test ile fonksiyonel aktivite ve dinlenim durumu bağlantısallığı ile test edilmiş, ilerleyen yaş ile birlikte korpus kollosum alanının azaldığı ve reaksiyon süresi ile ilintili olarak gençlere göre daha fazla ipsilateral birincil motor korteks aktivasyonları rapor edilmiştir [5].

Dinlenim durumu bağlantısallık çalışmalarının klinikteki uygulamaları ise, Alzheimer, MCI, ALS, ve bunama gibi hastalıklar üzerinde yoğunlaşmıştır. Alzheimer, MCI hastalarında varsayılan kip ağını (VKA) oluşturan bölgeler arasında korelasyon azalması ile VKA ve diğer ağlar arasındaki ters korelasyonda azalma izlenmiştir [6]. ALS hastaları üzerinde yapılan bir çalışmada ise VKA oluşturan bölgeler arasında ve somatomotor ağ içi korelasyon düşüşü görülmüştür [7]. Yapılan klinik çalışmaların genelinde VKA bileşeninde değişiklikler rapor edilmiştir.

Eğitim veya tecrübe ile oluşan beyin fonksiyonel farklılıkları incelendiği bir çalışmada ise profesyonel şekilde badminton sporunu gerçekleştiren atletler ve kontrol denekleri karşılaştırılmış ve badminton uzmanlarının kontrol deneklerinden fronto-pariyetal bağlantılarının farklılıklar içerdiği ortaya konmuştur [8].

Dinlenim durumu ölçümlerinin gerek klinik, gereksede araştırma uygulamaları ve bu çalışmalarda elde edilen sonuçlar, dinlenim durumu fonksiyonel beyin sinyallerinin işlenmesine yönelik algoritma ve yöntemlerin araştırılması ve geliştirilmesi için motivasyon yaratmakatdır.

Dinlenim durumu beyin ağları veya içsel bağlantı ağları (İBA), veri güdümlü veya tohum temelli yaklaşımlar ile hesaplanabilmektedir. Tohum temelli yaklaşımlarda birim hacim elemanı (voksel) seviyesindeki fMRG zaman serileri arasındaki korelasyon katsayısının (Pearson korelasyon katsayıs1) hesaplanması sonrası Fisher r->z dönüşümü ile vokseller arasındaki bağlantılara ulaşılmaktadır [9]. Buna karşın veri güdümlü yaklaşımlarda ise sıklıkla bağımsız bileşen analizi (Independent Component Analysis, ICA) yöntemi uygulanarak, BOLD uzay-zaman serisini birbirinden istatistiksel olarak bağımsız olan bileşenlere ayırmak hedeflenmektedir. ICA ilk olarak McKeown ve ark. tarafından fMRG verisine uygulanmıştır [10]. Voksellerden ölçülen zaman serisinin ayrıştırılması (dekompozisyon), birbirinden istatistiksel olarak bağımsız, geometrik olarak bağımsız veya frekans alanında farklı bilgiler içeren zaman serilerinin elde edilmesine olanak vermektedir. Bunun yanında, biyomedikal görüntü serileri veya zaman serileri üzerinde gerçekleştirilen sınıflandırma çalışmaları farklı 
durumlarda toplanan verilerin veya farklı hastalıkların belirlenmesinde önemli role sahiptir [15].

Doğrusal ve durağan olmayan sinyallerin zaman-frekans analizinde ise veri güdümlü bir metod olarak ampirik mod dekompozisyonu (Emprical Mode Decomposition, EMD) 2000 li yıllara doğru yaygınlaşarak uygulama alanı bulmuştur. EMD metodunun çok değişkenli versiyonu olan çokdeğişkenli ampirik mod ayrıştırımı (Multivariate Empirical Mode Decomposition, MEMD), çok noktadan ölçülen fizyolojik sinyallerin ayrışıtırmında kullanılmıştır [11].

$\mathrm{Bu}$ çalışma kapsamında, MEMD tekniği ile gerçekleştirilen ayrıștırma sonucunda elde edilen zaman serileri arasındaki koherans metriklerinin kullanıcı tarafından belirlenebilen bir eşik değeri ile süzgeçlenerek, frekans alanında yüksek korelasyon gösteren düğüm noktaları arasındaki bağlantısallığın haritalanması hedeflenmiştir. Beyin dokusunda seçilen tüm düğüm noktalarının arasındaki koherans bilgisi hesaplanarak, her noktanın olası bağantısallığı araştırılmaya çalışılmıştır.

\section{YÖNTEM}

\subsection{FMRG Ölçümü}

Çalışma kapsamında 19 gönüllüden Istanbul Universitesi Hulusi Behçet Yaşam Bilimleri merkezinde kurulu olan 3Tesla Philips MR cihazında EPI sekans 1 ile TR=2s, 2x2x2 mm birim hacim elemanı boyutlarıyla 6 dakika gözler kapalı şekilde ölçüm gerçekleştirildi. Ölçümleme öncesi katılımcılara gerçekleştirilen görüntüleme tekniği hakkında bilgi verildi ve yazılı onam formu okutuldu. Çalışma Marmara Üniversitesi, Klinik Araşıtrmalar Etik Kurulu, 09.2016.414 protokolo kodu ile onayland1.

Standart olarak, yeniden hizalama, çakıştırma, normalizasyon ve yumuşatma önişlemleri Matlab ortamında çalışan SPM8 aracıyla gerçekleştirildi [12]. Yumuşatılmış hacim serileri üzerinde MEMD uygulamasının ardından elde edilen zaman serilerinden Koherans bilgisi incelendi.

FMRG ile elde edilen görüntülerde uzaysal çözünürlük milimetre hasasiyetine ulaşmaktadır. Tüm beyin hacim elemanlarının analizlerde işleme alınması yüksek hesaplama maliyeti oluşturmaktadır. Bu nedenle, literatürde az sayıda düğüm noktasının ölçümlerinin analizi sıklıkla karşımıza çıkmaktadır. Bu çalışma kapsamında, fonksiyonel olarak özelleşmiş alanları gösteren anatomik beyin atlasından yola çıkılarak, 84 adet bölge esas alınmıştır. Şekil 1' de görüldüğü üzere, 84 bölge atlas üzerinden seçilerek, önişleme adımları sonrasında atlasa çakıştırılmış fMRG verileri (84 hacim elemanı x 214 ölçüm serisi) az sayıda değişkeni içerecek şekilde hesaplanmıştır.

\section{2. Çok değişkenli ampirik mod ayrıştırımı ve koherans}

EMD metodu, girdi zaman serisini, çeşitli sayıda içsel mod fonsiyonlarının (Intrinsic Mod Function, IMF) toplamı şeklinde açıklamaya çalışmaktadır. (1) numaralı formülde $y(t), t$ zamanındaki ölçülen veriyi, n IMF sayısını, $I_{i}(t), t$ zamanındaki i. IMF fonksiyonunun değerini ve $r_{n}(t)$ ise $t$ zamanındaki kalan (residuel) bilgiyi göstermektedir.

$y(t)=\sum_{i=1}^{n} I_{i}(t)+r_{n}(t)$

EMD metodunda, sinyalin yerel minimum ve yerel maksimumlarından elde edilen noktaların interpole edilmesi ile sinyalin zarfına ulaşılır. Interpolasyon ile elde edilen üst ve alt eğrilerin ortalaması alınarak $I_{i}$ ifadesine ulaşılır. Bu ifade girdi verisinden çıkartılarak osilatör kip elde edilir. Elde edilen osilatör ifade algoritmanın sonlanma kriterine uygun olursa, osilatör veri son içsel mod olarak atanır aksi halde osilatör ifade girdi olarak kullanılarak dekompozisyon işlemi sürdürülür.

MEMD metodunda ise çok değişkenli sinyallerin zarfları hesaplanıp, değişkenler üzerinden ortalaması alınarak yerel ortalamanın bir kestirimi gerçekleştirilir. Elde edilen $I_{i}$ ifadesi, girdi ölçümünden çıkartılarak geriye kalan veri üzerinde zarf hesaplama işlemi tekrarlanır. Yinelemeli şekilde süren işlem sonucunda durma kriteri sağlanana kadar süreç devam eder. Bu işlem sonrasında elde edilen zaman serileri arasındaki ilinti araştırılmıştır.

Zamansal alanda iki sinyalin arasındaki doğrusal ilinti korelasyon ile temsil edilirken, frekans alanında korelasyon koherans metriği ile gösterilmektedir. (2) numaralı denklemde $\mathrm{C}_{\mathrm{ij}}(\mathrm{w})$, w frekasında i. ve j. sinyaller arasındaki ilintiyi temsil etmektedir. $P_{i i}$ ve $P_{j j} i$ ve $j$ sinyallerinin güç spektrumunu, $P_{i j}$ ise çarpraz güç spektrumunu ifade etmektedir. Her w frekansı için ayrı bir koherans değeri hesap edilmektedir.

$C_{i j}(w)=\frac{P_{i j}(w)}{\sqrt{P_{i i}(w)+P_{j j}}(w)}$

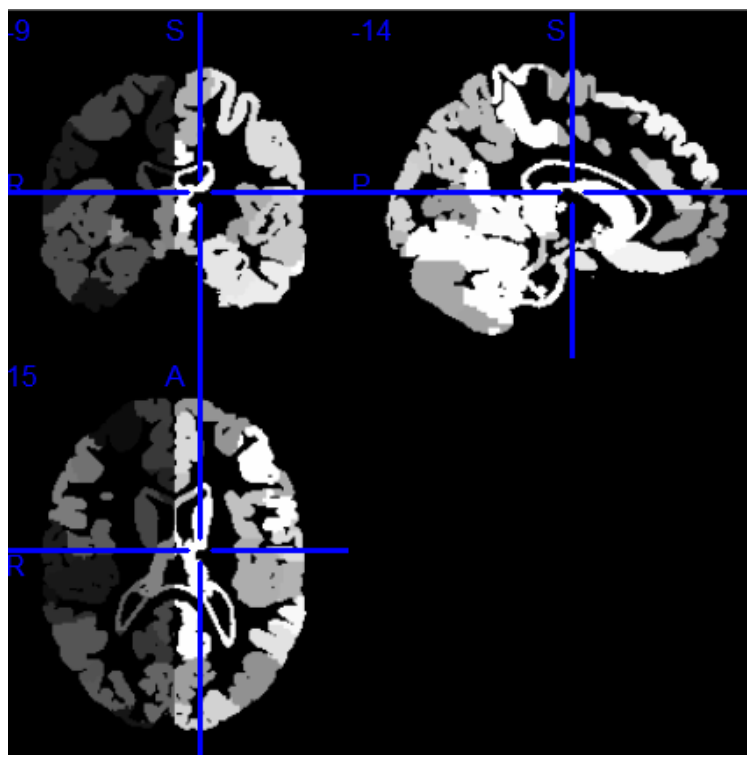

Şekil 1. Beyin dokusunun fonksiyonel bölütlenmesi sonucu elde edilmiş, gri renk ile kodlanmış atlas imgesinin, sagital, axial ve koronal örnek görüntüsü. 
MEMD uygulaması sonrasinda $0.007 \mathrm{~Hz}, 0.009-0.016 \mathrm{~Hz}$ aralı̆ $1,0.027-0.032 \mathrm{~Hz}$ ve $0.06-0.069 \mathrm{~Hz}$ bantlarındaki düğümler arası koherans bilgisi hesaplanmış ve denekler üzerinde olası tüm bağlantılar arasındaki koherans değerinin istatistiksel anlamlılık değeri permutasyon t-istatistiği ile araştırılmıştır.

Tek örneklem t-testine benzer olarak permutasyon tistatistiği temelli ortalamanın karşılaştırılması yöntemi, test edilen verinin Gauss dağılımına uygun olmadığı durumlarda da kullanılmaktadır. Çok değişkenli istatistik aynı anda gerçekleştirilerek, çoklu karşılaştırma düzeltmesi tmax yöntemi ile gerçekleştirilmiştir [13]. Permutasyon metodu, değişkenler arası korelasyon olduğu durumda, Bonferroni düzeltmesinden daha güçlü sonuçlar vermektedir. $\mathrm{Bu}$ çalışma kapsamında çoklu karşılaştırma düzeltmesi ile $\mathrm{p}<0.05$ anlamlılık değeri uygulanmıştır. 10000 permutasyon ve 3486 değişken için kritik t-eşik değeri 5.87 olarak seçilmiştir.

\section{SONUÇ}

Elde edilen alt zaman serilerinin her düğüm noktası için ayrı ayrı zaman bilgisi kullanılarak hesaplanan güç izgeleri Şekil $2,4,6$ ve 8 'de resim edilmiştir. 84 adet lokasyona ait zaman serileri 19 denek üzerinden ortalanarak elde edilen frekans spektrum izgelerine göre, bileşenlerdeki tepe frekanslar sirasiyla, $0.007,0.014,0.03$ ve $0.064 \mathrm{~Hz}$ civarında gözlenmiştir. Denekler üzerinden elde edilen ortalama tepe değerlerinin sırasıyla \%95 güven aralığı sınırları ise, 0.006 0.008, 0.011-0.017, 0.023-0.037 ve 0.054-0.074 Hz şeklinde gözlenmiştir.

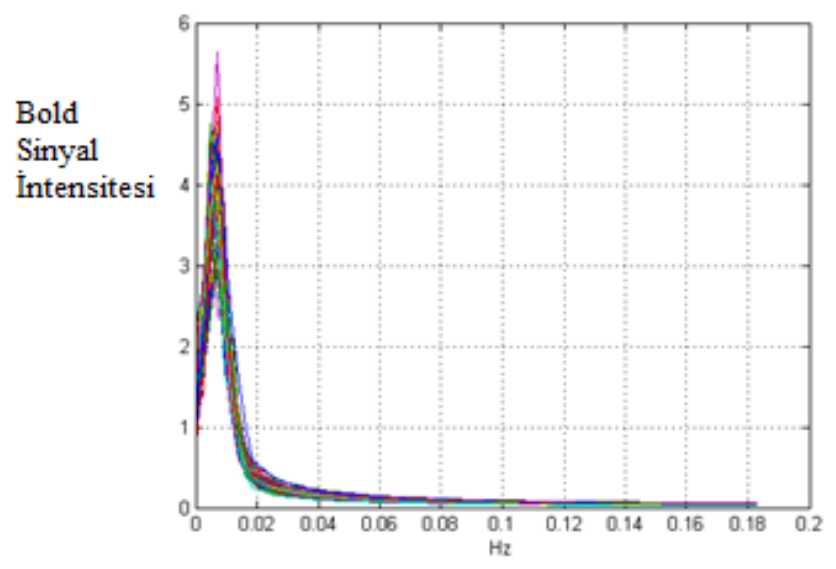

Şekil 2. Analiz sonucu elde edilen birinci bileşenin, belirlenen 84 noktadaki frekans spektrumlarının tüm denekler üzerinden ortalaması farklı renk serileri ile temsil edilmiştir.

Birinci bileşende istatistiksel anlamlı olan bağlantılar, oksipital lob lingual girus (BA17), limbik lob posteriyor singulat (BA30) ile oksipital lob Cuneus (BA30), temporal lob superiyor temporal girus (BA42) ile Pariyetal lob postsantral girus (BA2), limbik lob singulat girus (BA24), pariyetal lob postsantral girus (BA2) ile frontal lob parasantral lob (BA5), pariyetal lob postsantral girus (BA2) ile frontal lob presantral girus (BA4) ve pariyetal lob postsantral girus (BA3) şeklinde gözlenmiştir. Bağlantılar Şekil 3'de kortikal yüzey üzerinde görselleştirilmiştir.

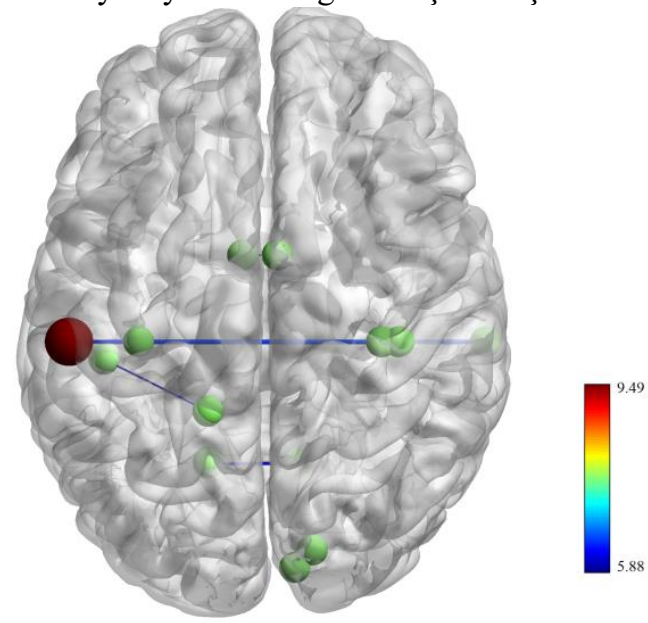

Şekil 3. MEMD yöntemi ile elde edilen birinci bileşenin tüm bağlantıların ortalamasından anlamlı $(\mathrm{p}<0.05)$ derecede yüksek bağlantıya sahip düğümler ve bağlantıları. Dügümlerin büyüklükleri, noktadan çıkan bağlantı sayıları ile belirtilmiştir. Bağlantıların renkleri ve büyüklükleri, düğüme gelen anlamlı bağlantı sayısına göre değer almaktadır (renk kodları t-istatistik değerlerini göstermektedir).

İkinci bileşende ise, temporal lob fusiform girus (BA37) ile frontal lob parasantral girus (BA5), oksipital lob lingual girus (BA17), limbik lob posteriyor singulat (BA30) ile oksipital lob Cuneus (BA30), limbik lob anteriyor singulat (BA33, BA24) ve pariyetal lob postsantral girus (BA3) bölgelerindeki bağlantısallık izlenmiştir. İkinci bileşene dair bağlantısallık haritası Şekil 5 'te gösterilmiştir.

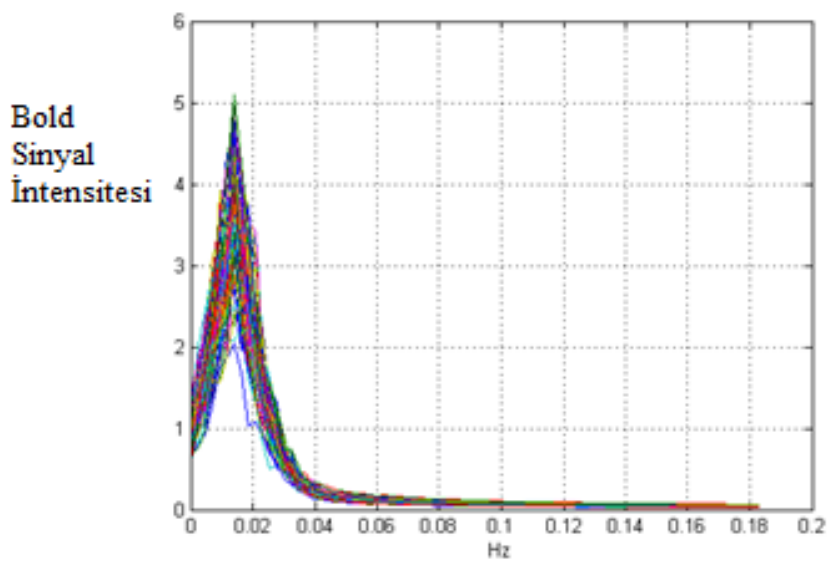

Şekil 4. Analiz sonucu elde edilen ikinci bileşenin, belirlenen 84 noktadaki frekans spektrumlarının tüm denekler üzerinden ortalaması farklı renk serileri ile temsil edilmiştir. 


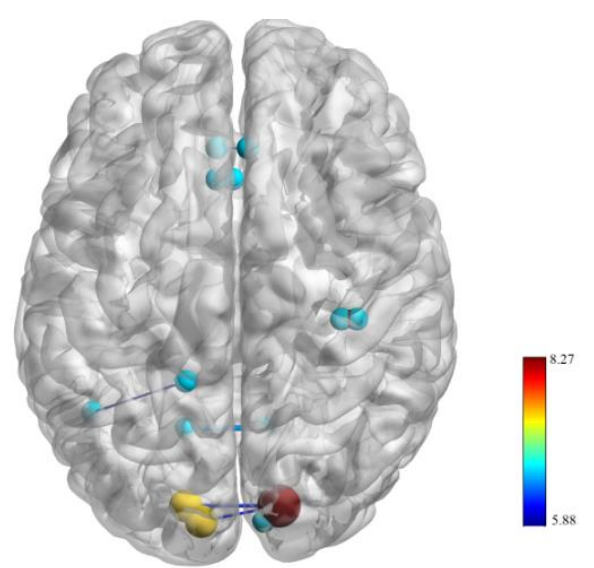

Şekil 5. MEMD yöntemi ile elde edilen ikinci bileşenin tüm bağlantıların ortalamasından anlamlı $(\mathrm{p}<0.05)$ derecede yüksek bağlantıya sahip düğümler ve bağlantıları.

Düğümlerin büyüklükleri, noktadan çıkan bağlantı sayıları ile belirtilmiştir. Bağlantıların renkleri ve büyüklükleri, düğüme gelen anlamlı bağlantı sayısına göre değer almaktadır (renk kodları t-istatistik değerlerini göstermektedir). Tepe frekansı $0.014 \mathrm{~Hz}$ civarında olan üçüncü bileşende ise, temporal lob fusiform girus (BA20) ile temporal lob orta temporal girus (BA21), temporal lob fusiform girus (BA20) ile oksipital lob lingual girus (BA17), temporal lob fusiform girus (BA20) ile frontal lob orta frontal girus (BA9), temporal lob fusiform girus (BA37) ile limbik lob posteriyor singulat (BA30), temporal lob fusiform girus (BA37) ile oksipital lob cuneus (BA30), temporal lob fusiform girus (BA37) ile pariyetal lob inferiyor pariyetal lobule (BA40), temporal lob fusiform girus (BA37) ile frontal lob parasantral lobule (BA5), insula ile postsantral girus, precuneus (BA31), limbik lob singulat girus, frontal lob inferiyor frontal girus (BA45) ile frontal lob presantral girus (BA4), frontal lob presantral girus (BA44) ile frontal lob orta frontal girus (BA9), frontal lob orta frontal girus (BA9) ile limbik lob singulat girus (BA24) ve frontal lob orta frontal girus ile parasantral lobule arası bağlantılara ulaşılmış olup, bu bağlantılar Şekil 7' de gösterilmiştir.

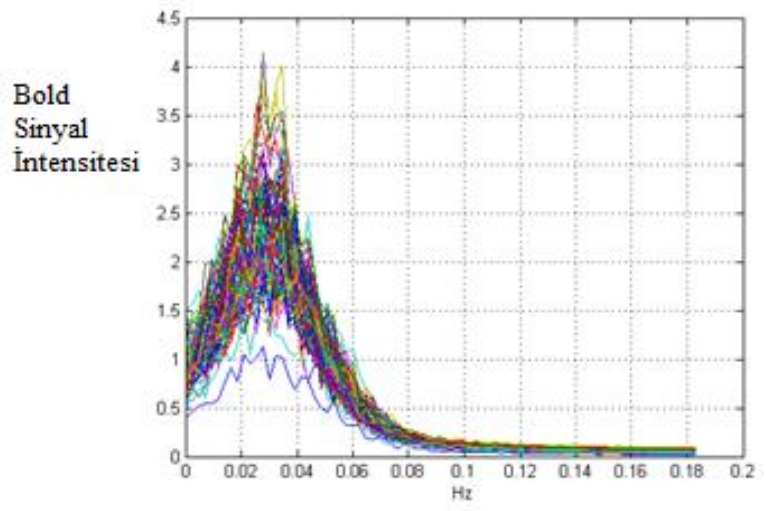

Şekil 6. Analiz sonucu elde edilen üçüncü bileşenin, belirlenen 84 noktadaki frekans spektrumlarının tüm denekler üzerinden ortalaması farklı renk serileri ile temsil edilmiştir.

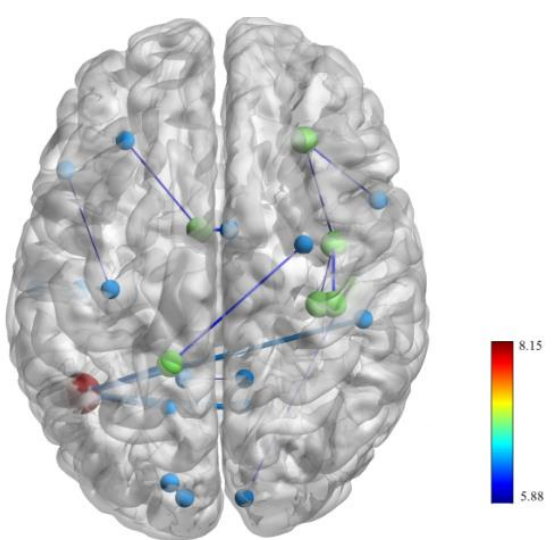

Şekil 7. MEMD yöntemi ile elde edilen üçüncü bileşenin tüm bağlantıların ortalamasından anlamlı $(\mathrm{p}<0.05)$ derecede yüksek bağlantıya sahip düğümler ve bağlantıları. Düğümlerin büyüklükleri, noktadan çıkan bağlantı sayıları ile belirtilmiştir. Bağlantıların renkleri ve büyüklükleri, düğüme gelen anlamlı bağlantı sayısına göre değer almaktadır (renk kodları t-istatistik değerlerini göstermektedir)

Dördüncü bileşenin tepe frekansı $0.064 \mathrm{~Hz}$ civarında Şekil 8'de izlenmektedir. Anlamlı bağlantılar ise Şekil 9'da gösterilmiştir. Temporal lob fusiform girus (BA20) ile temporal lob orta temporal girus (BA21), temporal lob superiyor temporal girus (BA38) ile pariyetal lob inferiyor pariyetal lobule (BA40), limbik lobe parahipokampal girus (BA28) ile pariyetal lob inferiyor pariyetal lob (BA40), temporal lob fusiform girus (BA37) ile pariyetal lob inferiyor pariyetal lobule (BA40), temporal lob fusiform girus (BA37) ile frontal lob parasantral lob (BA5), limbik lob anteriyor singulat (BA24) ile pariyetal lob inferiyor pariyetal lobule (BA40) ve pariyetal post santral girus (BA3) bağlantıları izlenmiştir.

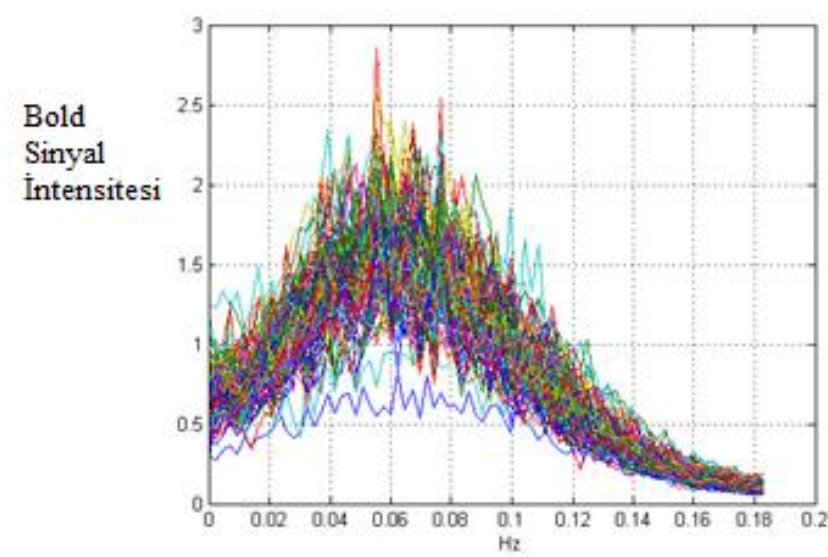

Şekil 8. Analiz sonucu elde edilen dördüncü bileşenin, belirlenen 84 noktadaki frekans spektrumlarının tüm denekler üzerinden ortalaması farklı renk serileri ile temsil edilmiştir. 


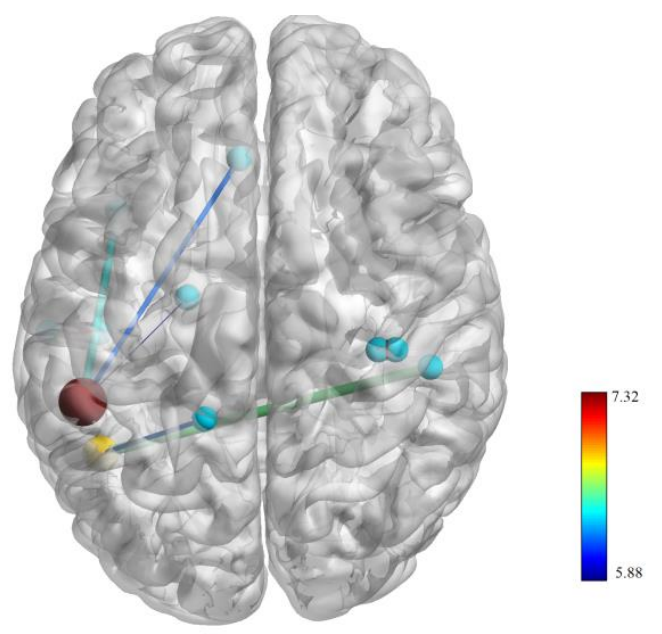

Şekil 9. MEMD yöntemi ile elde edilen dördüncü bileşenin tüm bağlantıların ortalamasından anlamlı $(\mathrm{p}<0.05)$ derecede yüksek bağlantıya sahip düğ̈̈mler ve bağlantıları.

Düğümlerin büyüklükleri, noktadan çıkan bağlantı sayıları ile belirtilmiştir. Bağlantıların renkleri ve büyüklükleri, düğüme gelen anlamlı bağlantı sayısına göre değer almaktadır (renk kodları t-istatistik değerlerini göstermektedir).

\section{DEĞERLENDİRME}

Dinlenim durumu içsel bağlantı ağları frekans spektrumu 0.01 ile 0.15 arası değerler aldığı düşünüldüğünde, fMRG ölçümlerinin örnekleme frekansını $0.5 \mathrm{~Hz}$ olarak belirlemek $(\mathrm{TR}=2 \mathrm{~s}$.$) , bileşenlerin izlenmesine olanak vermektedir.$ Yakın zamanda yapılan bir çalışmada fMRG örnekleme frekansını $1.5 \mathrm{~Hz}$ seviyesine çıkaran araştırmacılar, dinlenim durumu içsel bağlantı ağlarının özellikle VKA, frontopariyetal, dorsal dikkat ve görsel ağın birden fazla frekans bandında gözlendiğini ortaya koymuşlardır.

Tohum noktası ve ilişkili kontralateral nokta arasında hemisferler arası bağlantısallığın tüm frekans bantlarında gözlendiği halde, tohum temelli korelasyon haritalarının uzaysal genişliğinin $0.198-0.5 \mathrm{~Hz}$ ve $0.5-0.75 \mathrm{~Hz}$ bantlarında azaldığı ortaya konmuştur [13]. Bu çalışma kapsamında, dinlenim durumu BOLD sinyali $0.25 \mathrm{~Hz}$ frekansina kadar bilgi içerebilmektedir ve düşük frekans bileşenlerinde bilateral bağantılar MEMD analizi sonrasında gözlenmiştir. Beklendiği üzere dinlenim durumu fonksiyonel kanlanma aktivitesi 0 ile $0.08 \mathrm{~Hz}$ frekans aralığında yüksek, 0.08-0.16 $\mathrm{Hz}$ aralığında ise görece daha düşük olarak görülmektedir.

Yapılan analiz sonucunda elde edilen birinci bileşende, görsel ağ ve işitsel fonksiyonların yürütülmesinde rol oynayan süperiyor temporal girus bağlantıları izlenmiştir.

Anteriyor singulat ve posteriyor singulat bölgelerindeki ikinci bileşen için gözlenen yüksek koherans, ikinci bileşenin VKA nın bir parçası olduğunu desteklemektedir. Ayrıca ikinci bileşende güçlü bir görsel ağ bağlantı mekanizmasıda izlenmiştir.
Literatürde $0.12 \mathrm{~Hz}-0.2 \mathrm{~Hz}$ frekans aralığını VKA ile ilişkilendiren çalışmalar mevcutdur [14]. MEMD uygulaması sonrasında elde edilen bileşenlerin birinci ve ikincisinde VKA bağlantı ağının önemli bileşenlerine ulaşılmıştır.

İkinci bileşene benzer olarak, üçüncü bileşende VKA posteriyor bağlantılarını ortaya koymaktadır.

Üçüncü bileşende, ek olarak bilateral pariyetal ve sol frontal ve sağ frontal bağlantıların varlığı, bu bileşenin sağ fronto pariyetal dikkat ve sol fronto pariyetal dikkat ağını temsil ettiğini düşündürmektedir. Gohel ve Biswal (2015) tarafından gerçekleştirilen çalışmaya uyumlu olarak [13], bu çalışmada üçüncü bileşene tekabül eden dikkat ağının frekans spekturumu $0.03 \mathrm{~Hz}$ de tepe yapmaktadır ve $0.06 \mathrm{~Hz}$ e kadar ulaşmaktadır. Üçüncü bileşende gözlenen posterior singulatın, VKA'nın önemli bir düğümü olarak Zhang ve ark. çalışmasında elde ettikleri frekans spektrumu ile uyumluluk göstermiştir [11].

Superiyor temporal girus bağlantıları frekans spektrumu açısından literatürle uyumlu olarak en yüksek frekans spektrumuna ait dördüncü bileşende gözlenmiştir [14].

MEMD metodu ile elde edilen zaman serilerinin koherans metriği ile gruplanması ve incelenmesi, aynı uzaysal bölgelerin farklı spektral bantlarda kurduğu bağlantıları incelemek adına önem taşımaktadır. Ölçülen zaman serilerine öncül bir bilgi sunmadan, veri güdümlü olarak zaman serisi ayrışımı ile yansız bir dekompozisyon elde edilebilmektedir.

\section{TEŞEKKÜR}

Bu çalışma Kalkınma Bakanlığı proje no 2010K120330 desteğiyle gerçekleştirilmiştir.

\section{KAYNAKÇA}

[1] K.J. Friston, C.D. Frith, P.F. Liddle, R.S.J. Frackowiak, "Functional connectivity: the principal component analysis of large (PET) data sets.” J. Cereb. Blood Flow Metab. 13, 5-14, 1993.

[2] S. Ogawa, T. M. Lee, A. R. Kay ve D. W. Tank, "Brain magnetic resonance imaging with contrast dependent on blood oxygenation.” Proc. NatI. Acad. Sci., 87(1990), 98689872.

[3] B. Biswal, F. Zerrin Yetkin, V.M. Haughton ve J.S. Hyde. "Functional connectivity in the motor cortex of resting human brain using echo-planar MRI." Magn. Reson. Med. 34, 537-541, 1995.

[4] H. Littow, A. A. Elseoud, M. Haapea, M. Isohanni, I. Moilanen, K. Mankinen, J. Nikkinen, J. Rahko, H. Rantala, J. Remes, T. Starck, O. Tervonen, J. Veijola, C. Beckmann ve Vesa J. Kiviniemi, "Agerelated differences in functional nodes of the brain cortex - a high model order group ICA study." Frontiers in Systems Neuroscience 4(32) 2010

[5] J. Langan, S. J. Peltier, J. Bo, B. W. Fling, R. C. Welsh ve R. D. Seidler, "Functional implications of age differences in motor system connectivity." Frontiers in Systems Neuroscience, 4(17)June 2010 
[6] S. J. Li, Z. Li, G. Wu, M. J. Zhang, M. Franczak ve P. G. Antuono. "Alzheimer disease: evaluation of a functional MR imaging index as a marker." Radiology 225, 253-259. , 2002.

[7] B. Mohammadi, K. Kollewe, A. Samii, K. Krampfl, R. Dengler ve T. F. Munte,. "Changes of resting state brain networks in amyotrophic lateral sclerosis." Exp. Neurol. 217, 147-153, 2009.

[8] X. Di, S. Zhu, H. Kin, P. Wang, Z. Ye, K. Zhou, Y. Zhuo ve H. Rao "Altered Resting Brain Function and Structure in Professional Badminton Players", 2(4), Brain Connectivity, 2012

[9] S. Whitfield-Gabrieli ve A. Nieto-Castanon, "Conn: A Functional Connectivity Toolbox for Correlatedand Anticorrelated Brain Networks", Brain Connectivity, Vol 2, No 3, 2012, DOI: 10.1089/brain.2012.0073, 2012.

[10] M.J. McKeown, S. Makeig, G.G. Brown, T.P. Jung, S.S. Kindermann, A.J. Bell, T.J. Sejnowski. "Analysis of fMRI data by blind separation into independent spatial components.” Human Brain Mapp. 1998; 6(3):160-88.
[11] T. Zhang, P. Xu, L. Guo, R Chen, R. Zhang, H. He, Q. Xie, T. Liu, C. Luo ve D. Yao. "Multivariate empirical mode decomposition based sub-frequency bands analysis of the default mode network: a restingstate fMRI data study." Applied Informatics 2015 2(2) DOI: 10.1186/s40535-0140005-z,

[12] K.J. Friston, J. Ashburner, C.D. Frith, J.B. Poline, J. D. Heather, R.S. Frackowiak. "Spatial registration and normalization of images.", Human Brain Mapping. 1995:3:165-18,

[13] R.C. Blair ve W. Karniski, “An alternative method for significance testing of waveform difference potentials. " Psychophysiology, (1993)

[14] S. R. Gohel ve B. B. Biswal. "Functional Integration Between Brain Regions at Rest Occurs in MultipleFrequency Bands." Brain Connectivity, 5(2015), 23-34.

[15] K. Akyol. "Meme Kanseri Tanısı İçin Özniteliklerin Öneminin Değerlendirilmesi Üzerine Bir Çalışma". Akademik Platform Mühendislik ve Fen Bilimleri Dergisi 6 $\begin{array}{llll}1 & 2 & \text { (Ağustos 2018): } & 109-115 .\end{array}$ http://dx.doi.org/10.21541/apjes.323336 